\section{The Baltimore Oriole}

\section{Arthur Ward, Swift Current}

There is scarcely a season that we do not observe the ingenuity of the Yellow Warbler in dealing with the persistent intrusion of the Cowbird. Other birds, too, have demonstrated the ability to cope with interference in this respect. Usually in the spring, before the migratory birds appear House Spaxrows take possession of the choice nest building sites adjacent to the iraps. Wishing to reserve these for the ones we hope to trap and band, the Sparrows have to be discouraged. Later on they seek the close proximity of other birds fur ther away and will even chum up close to the Kingbird.

Later in the incubation season, whilst working in the garden, my attention was drawn to the presence of a pair of Baltimore Orioles. Entering the grove raised a clamor of protests-every species seemed to be there piping notes of distress, such as one would hear if an owl were present. Looking up into the branches I could see the delicately woven gourd-like structure-the masterpiece of Lady Baltimore. Hanging by the neck over the side of the nest, hidden by binder twine was a dead young sparrow. So securely was it fastened that when I reached up and pulled, its head was left hanging by the string. On the other side was another dead sparrow and still another one lying dead in the nest. The only occupant was a sprightly Baltimore fledgling.

Both the Baltimore parents and the sparrows vied in hauling goods to feed the lively youngster. Failing to acquire total possession of the nest, the sparrows had jointly aided incubation. Strange as it may seem, sparrows never attempt to take possession of Oriole nests which sometimes are finished and then abandoned.

A flashing gem of orange and black, flitting from tree to tree, intoning intermittingly in $\mathrm{rich}$ contralto "Peter Pan" - easily trapped for banding purposes - the Baltimore Oriole is a most useful and ornamental tenant of one's Grove.

\section{"Waterfowl Banding 1939-1950 by Ducks Unlimited"}

Winnipeg, Man., Oct. 1952 Dr. Stuart Houston

This 53-page booklet summarizes results from the banding of 63,826 waterfowl by Ducks Unlimited between 1939 and 1950. 22,270 birds were banded in Saskatchewan, many of them near Yorkton $(6,710$ by J. $\mathrm{H}$. Wilson, 5,011 by Stuart Houston). Fred Bard banded 3,093 near Regina.

Somewhat more than $10 \%$ of these birds were subsequently heard from. Maps and tables show the travels of these birds, subdivided to show such facts as age, species, province of origin, state recovered from, etc. Some species seem to have a greater "hunting pressure" than otherse.g. $18.6 \%$ of the Redheads, $15.6 \%$ of the Mallards and only $3.9 \%$ of the Blue-winged Teal were recovered. Other information includes a list of birds trapped at the same locality in subsequent years, a list of recoveries indicating an eastern migration route through Ontario, and evidence of a post-breeding northward movement. Of 6,855 recoveries, only 114 reached the age of five years or more.

Appropriately, the cover photograph depicts the late Mrs. Priestly releasing a banded duck at Rousay Lake.

\section{A Hint from the President}

To indentify birds, one needs a good book-and the BEST book of the many available is Peterson's "FIELD GUIDE TO THE BIRDS." Lavishly illustrated, it makes identification simple. Every member should own one. (Do not be trapped into buying the guide to the Western birds-it is for the Rockies and the Pacific Coast). The book is $\$ 4.25$ at any bookstore-e.g.-Logan's Drug \& Book, Yorkton; Canada Drug \& Book, Regina; or T. Eaton Co. 